\title{
IDENTIFICATION OF POTENTIAL SITES FOR WATER HARVESTING STRUCTURES USING GEOSPATIAL TECHNIQUES AND MULTI-CRITERIA DECISION ANALYSIS
}

\author{
Arnab Saha*, Manti Patil, Sateesh Karwariya, S. M. Pingale, Samee Azmi, V. C. Goyal, D. S. Rathore \\ RMO Division, National Institute of Hydrology, Roorkee, India - \\ (arnab.dd, patilkgp, sateesh.karwariya, pingalesm, samiazmi)gmail.com
}

\author{
Commission V, WG V/4
}

KEY WORDS: Water harvesting structures, Remote sensing and GIS, Watershed management, MSE, AHP

\begin{abstract}
:
Changing hydrological phenomenon and increase the water demand in all sectors create a huge problem of water scarcity. Precipitation is one and only major source to mitigate this problem. In Central India, the average annual precipitation is sufficient in most of the part but not capable to harvest and utilize during the summer season. Identification of suitable site for water harvesting structures plays a key role to enhance the water level for watershed management. In the present study, suitable sites have been demarcated to build up a water resource development plan in Mandri river watershed of Kanker district, Chhattisgarh using Remote Sensing and GIS techniques. Basic guidelines of Integrated Mission for Sustainable Development (IMSD) have been used for identifying the suitable sites for water harvesting structures. Remote Sensing and GIS are used for site suitability analysis of water harvesting structure to extract the information of various features such as lineament, land use/land cover, soil, slope, lithology, geomorphology, drainage order, rainfall etc. In order of importance, we have assigned weights to each feature. Slope and design discharge are key parameters in site suitability analysis, so that we assigned maximum weight to this parameters. A possible site suitability map for water harvesting/conservation structures was derived following an Analytical Hierarchy Process (AHP) and Multi-Criteria Decision Analysis (MCDA). This work attempts to identify the probable zone for water harvesting structures such as boulder check/gabion, gully plug/bori bandhan, check dams and stop dams. Multi-criteria analysis is applied in GIS to assist the decision-makers in determining appropriate zones for water harvesting structures in view of external characteristics of the watershed. Further, using weighted overlay method, the catchment was grouped into categories of suitable or highly suitable.
\end{abstract}

\section{INTRODUCTION}

Water, one of the most vital natural resources for the survival of life is depleting quickly in urban areas as well as rural areas, mainly because of population increase at an alarming rate, with an increase in agricultural and domestic demands (Kumar et al., 2008). It highlights water scarcity mainly in Rabi and Zaid season (Naseef et al., 2015). Due to the increase in water demand in different sectors and insufficient source of availability, India is moving backward in agriculture contribution towards GDP. The source of rainfall is a natural phenomenon and cannot be changed, but water conservation is one of the important task to minimize the water poverty during non- monsoon season. Different water conservation practices apply to reduce surface runoff and divert it to recharge zones in order to increase moisture as well as crop production (Lesschen et al., 2007; Krois and Schulte, 2014). Reliable runoff conservation can allocate water efficiently for competing water users like hydropower generation, agricultural and domestic for maintenance of environmental flows (Patil et al., 2016).

The structures that are built for watershed management implies an overall improvement in water-scenario and hence increase in biomass so as to fulfill the people's basic needs in an existing watershed. The approach mainly focuses on reducing runoff, soil loss and augmentation of infiltration.
By constructing suitable structures is one of the practices for a reduction in surface runoff by changes in land management, which in turn will increase infiltration and aid water conservation (Ramakrishnan et al., 2008). In this study, the suitable sites for constructing water harvesting structures in the watershed are identified using the Analytical Hierarchical Process (AHP). Identification of most probable sites for water conservation structures needs a large volume of multidisciplinary inputs from different sources for which the applications of modern remote sensing and geographic information system (GIS) techniques have gained much interest in recent years (Ramaswamy \& Anbazhagan, 1997). For the selection of suitable sites, many guidelines have been used by various agencies. Guidelines such as the Integrated Mission for Sustainable Development (IMSD), Food and Agriculture Organisation (FAO) etc. In this study, selection of water harvesting structure is done on the basis of IMSD guidelines put forwarded by the National Remote Sensing Agency (NRSA), Hyderabad (Naseef and Thomas, 2016). Therefore, the main objective of this study is to present a reasonably robust methodology for assessing water harvesting potential zone and identifying suitable sites/zones for different water harvesting structures according to the priority of watershed characteristic using Remote Sensing, GIS, and AHP techniques.

* Corresponding author 


\section{STUDY AREA AND DATA USED}

Mandri river watershed lies in the Kanker district of Chhattisgarh, India. It is located between $20.1990^{\circ} \mathrm{N}$ latitude and $81.0755^{\circ} \mathrm{E}$ longitude, having a total geographical area of $66.70 \mathrm{~km}^{2}$ (Figure 1). The region comprises of nine villages and 10 micro-watersheds and it falls in the Middle Mahanadi basin. Mandri river is the major stream flowing through the area. On an average, the region experiences an annual rainfall of around $1297 \mathrm{~mm}$ approximately $90 \%$ of which falls during the period from June to October. The average annual rainfall has fluctuated greatly over the last six years. Agriculture is the major

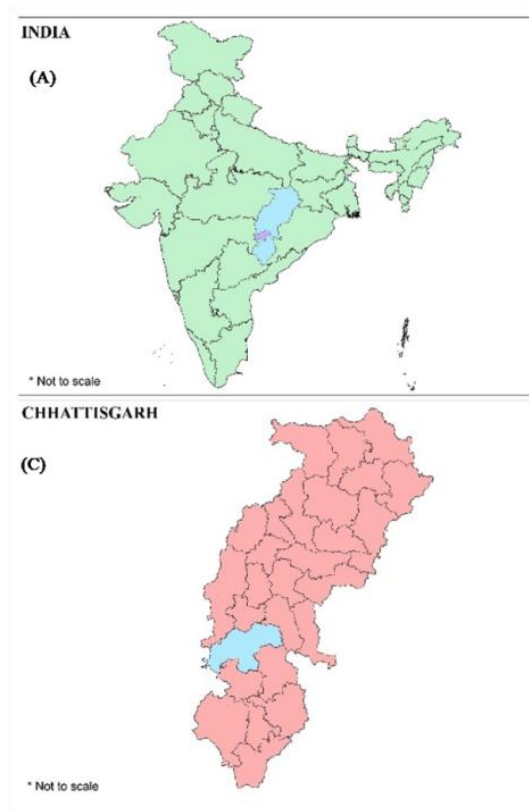

activity for a livelihood and majority of the rainfall occurs in the Kharif season thereby making it a rainfed region. The topography of the watershed is undulating. The watershed has a maximum elevation of $711 \mathrm{~m}$ above mean sea level and minimum elevation of $330 \mathrm{~m}$ above msl.. The overall drainage pattern of the watershed is dendritic. The climate of the watershed is semi-arid with four seasons. The different data was used for identifying water harvesting structures sites in the selected watershed such as Rainfall (Add how many years-duration), soil, Land use/Land cover, DEM, Slope, runoff potential, drainage density, Lithology and design peak discharge

Figure 1: Study area map of Mandri river watershed

\section{METHODOLOGY}

The identification of suitable areas for water harvesting is a multi-objective and multi-factors problem. The thematic

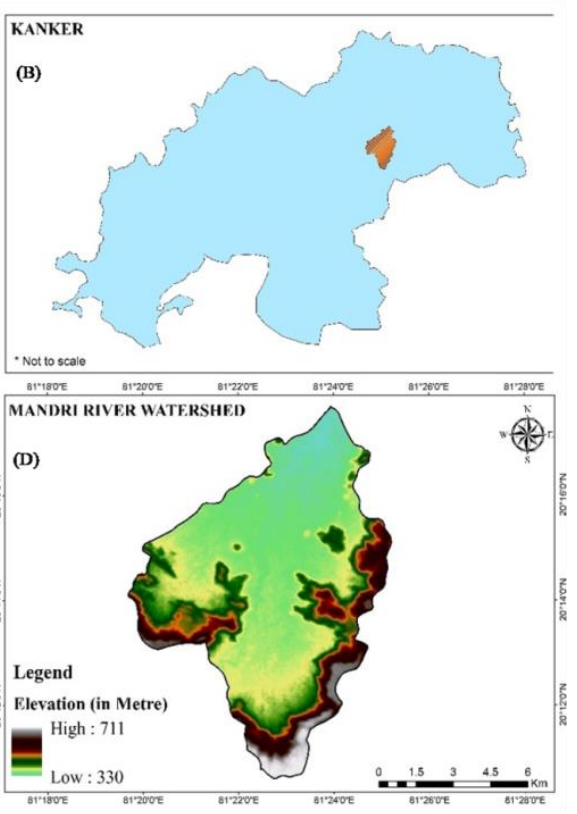

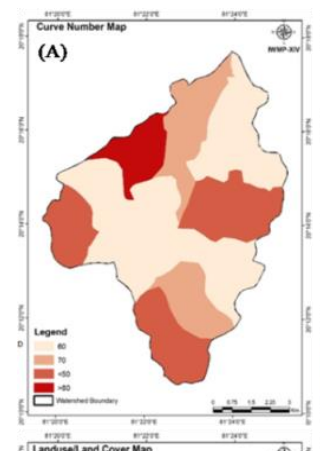
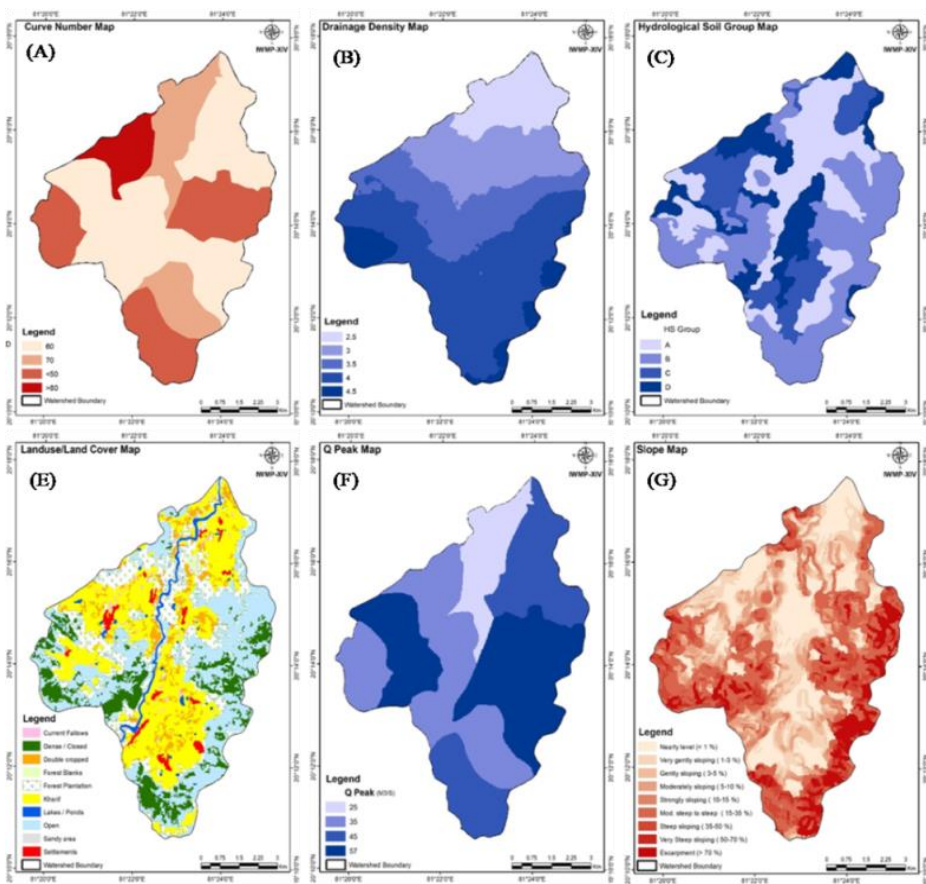

Figure 2: Maps of all thematic layers input database has been prepared using primary and secondary data using remote sensing and GIS (Figure 2). 
The major steps adapted in the study were given as follows and presented in Figure 3:

- Selection of factors

- Suitability levels assessment of the factors for water harvesting

- Assignment of weights to these factors

- Collection of spatial data for the factors through various sources, including a GPS survey to supplement and generate maps using GIS tools.

- Generation of suitability maps.

Technical guidelines suggested by the Integrated Mission for Sustainable Development (IMSD) has been adopted for selecting suitable sites for water harvesting structures.
Conventional site-specific data and remote sensing data for the study area were collected from various government agencies. Soil maps (1:250,000 scale) have been used in the present work, while land use/land cover map at 1:50,000 have been derived from satellite imagery. According to AHP technique, the suitable weights assigned to each thematic layer, which are used as an input parameter to specify suitable sites for water harvesting/conservation structures, considering, the characteristics of their influence over recharge (Kumar et al., 2008). AHP expert opinion based weight assignment has been carried out for each thematic layer and they have been integrated and analyzed by using the weighted overlay method (Figure 3 ).

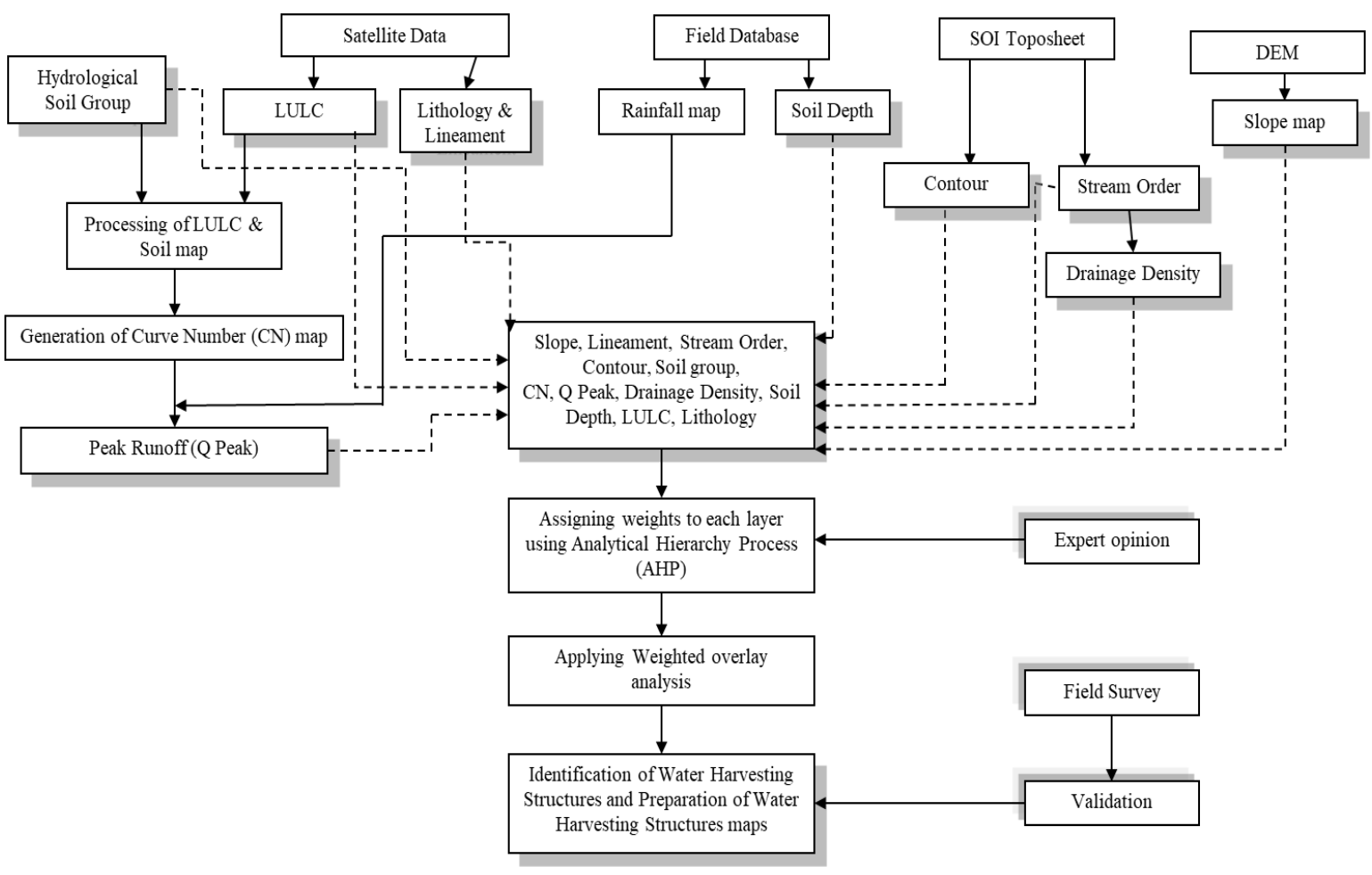

Figure 3: Flowchart of Methodology

\subsection{Analytic Hierarchy Process (AHP)}

AHP is one of the specific methods of site suitability of structures, which is based on Multi-Criteria decisionmaking technique that was originally developed by Prof. Thomas L. Saaty (1987). In the identification of suitable sites for water storage, this method is used to determine the percentage importance of the parameters in accordance with the guidelines laid by IMSD. The AHP procedure performs a comparison of various parameters within a set of reciprocal matrices. The ranking from 1 to 9 was assigned, different to each unit in theme, on the basis of their significance with reference to their site selection for installing water-harvesting structures. In this ranking, where ' 1 ' denotes the restricted area and no structure is proposed for that area and ' 9 ' denotes excellent zone for site selection for rainwater harvesting structures (Kumar et al., 2008).
In order to check the consistency of weights assigned to different themes and their features, the 'Consistency Ratio' as suggested by Saaty (1980) was calculated using the following equation:

$$
\text { Consistency Ratio }(\mathrm{CR})=C I / R C I
$$

Where, RCI is random consistency index and CI is consistency index, which is given as:

$$
C I=\left(\boldsymbol{\lambda}_{\max }-n\right) /(n-1)
$$

Where, $\boldsymbol{\lambda}_{\max }$ is principal eigen-value computed by eigenvector technique and $\mathrm{n}$ is the number of criteria (factors).

Saaty (1980) recommended that the value of CR should be less than 0.1 ; otherwise, the weights should be re-evaluated to maintain consistency. 


\subsection{IMSD guidelines}

Suitable sites for water harvesting structures were identified using IMSD guidelines (1995) and FAO (1977) guidelines. Error! Reference source not found. shows the specifications for water harvesting/recharging structures as per IMSD guidelines. Socio-economic data, water demand data and cadastral information for identifying the exact location of different water harvesting structures have also been used.

Table 1: IMSD guidelines

\begin{tabular}{|c|c|c|c|c|c|}
\hline Structure & Slope (\%) & $\begin{array}{c}\text { Porosity \& } \\
\text { Permeability }\end{array}$ & Runoff potential & $\begin{array}{c}\text { Stream order } \\
\text { Catchment area } \\
\left(\times \mathbf{1 0}^{\mathbf{4}} \mathbf{~ m}^{\mathbf{2}}\right)\end{array}$ & $1-2$ \\
\hline Farm ponds & $0-5$ & Low & Medium/High & 1 & $>25$ \\
\hline Check dams & $<15$ & Low & Medium/High & $1-4$ & $>4$ \\
\hline Subsurface dyke & $0-3$ & High & Medium/Low & 1 & - \\
\hline Gully plug & $15-20$ & Low & High & $1-4$ & $25-40$ \\
\hline Percolation pond & $<10$ & High & Low & $>5$ \\
\hline
\end{tabular}

\subsubsection{Check Dam}

Check dams are one of the popular water harvesting structures and mostly applied in central India region.( Khonkaen et al .2011)Check dams are of greater importance as it addresses water conservation as well as soil erosion. In general, check dams are usually suggested for lower order streams (up to third order), the slope of the terrain should be between flat to gentle slope in order to retain a maximum possible quantity of water which comes under the L-section. These structures are usually proposed where water table fluctuations are very high and the stream is influent and or internally effluent. For an economical design, the catchment area should be more than 25ha. This structure is suitable for soil type of less to medium permeable, to allow infiltration to the downstream side of the dam if necessary. It should be located in the area, which has a higher potential for crop production and settlement areas to allocate the harvested water (Rao et al., 2005).

\subsubsection{Boulder Check/Gabion}

A gabion wall is a retaining wall made of stacked stonefilled gabions tied together with wire. Gabion walls are usually battered (angled back towards the slope), or stepped back with the slope, rather than stacked vertically. (Morais et al., 2006)

\subsubsection{Gully Plug/Bori Bandhan}

Gully plugs are mainly built to prevent erosion and to settle sediments and pollutants. Furthermore, it is possible to retain soil moisture due to infiltration. Gully plugs can be defined as stones placed across gullies or valleys, so as to capture nutrients, silt, and moisture. It is an effective method to slow down the speed of flowing water of the stream in any area. Bori bandhan are constructed during peak flow across the drainage line of the field with cement bags filled with soil/sand to check the flow of water.

\subsubsection{Stop Dam}

Stop dam is an artificial lake which is built in somewhat hilly areas or a region where the slope is relatively higher surface exists to fulfill the need of water for, especially irrigation purposes.

\section{RESULTS}

Identification of suitable sites for water harvesting structure plays a crucial role in maximum recharge and conservation of soil and water. Watershed characteristic is one and the only source which suggests locating the structure in a proper way. The AHP (Saaty and Vargas 1991) used in this work to assign the weights to various watershed parameters that is mainly considered to identify the site and structure of watershed areas. We have considered the eight thematic layers such as Hydrological Soil group, Soil Depth, Land use and Land cover (derived from available Remote Sensing data), Slope (derived from DEM), CN Runoff potential, Drainage density, Lithology, design discharge etc (Figure 2). The weights are assign from 1-9 according to the importance of thematic layers and normalized it between 0 and 100, which shown in Figure 4. 

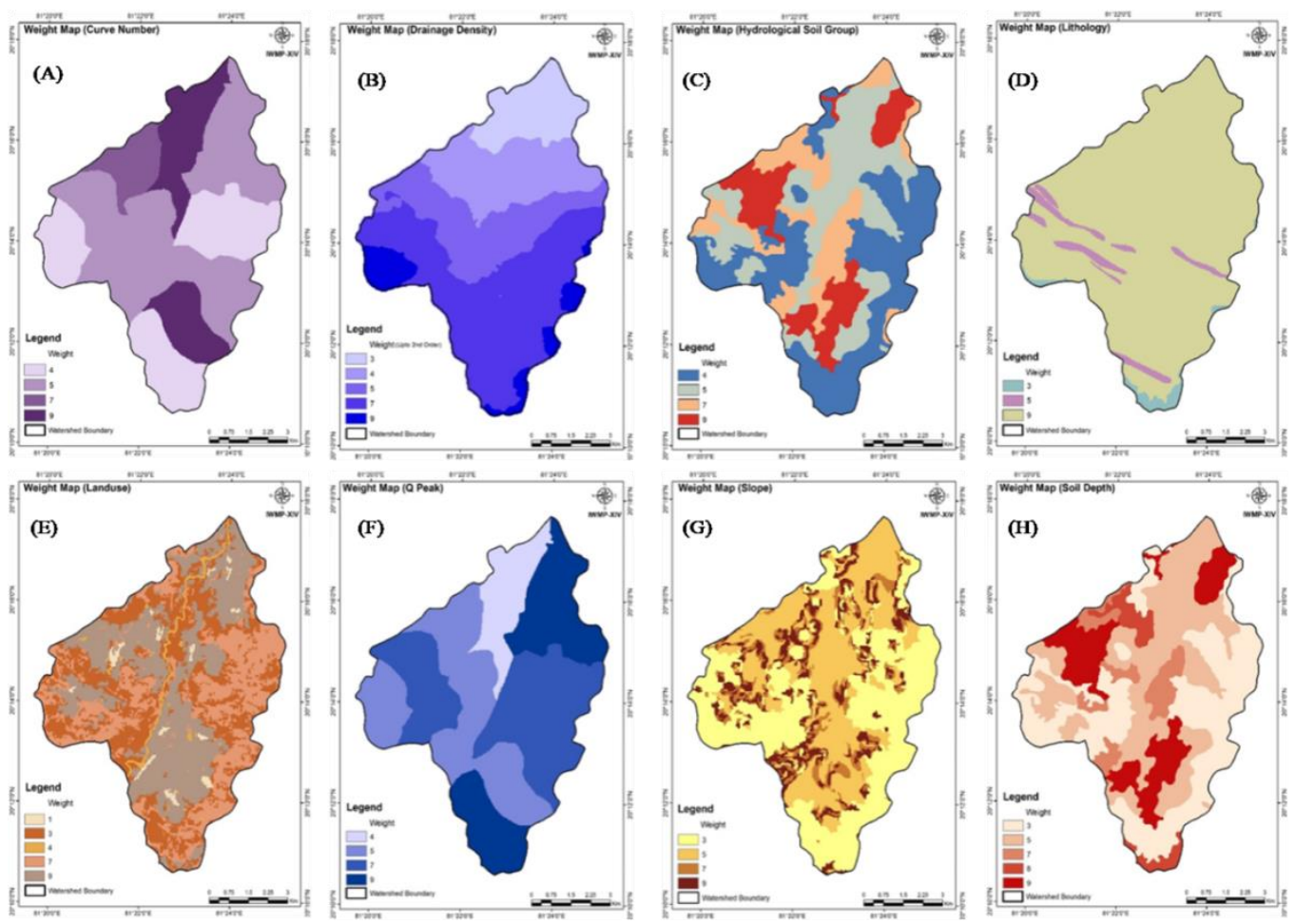

Figure 4: Weight assigned to each thematic layers

The weights are assigned to each thematic layers based on AHP. Each layer is then internally ranked, based on the classes it possesses and then prioritized. With the importance of thematic layers, the features classes that are mentioned in Error! Reference source not found. have also an equal importance to identify the suitable sites. To get precise results each layer is subclassed likes slope classified into six different categories like 1-3,3-5,5-10,10$15,15-30,>30$ and according to the priority of each category, weights are assigned like 5,7,9,7,3,3. The study area is quite small and topography is undulating so that identification of a suitable site for water harvesting structure is a challenging task. So that to minimize the approximation and tradition approaches, we have classified the thematic layer to possible maximum subclasses. This geospatial technique is in the recent trend to the identified potential site for water harvesting structure.

To identify the probable zones of water harvesting structures, it is very challenging to identify the exact location of each structure, using Remote sensing and GIS. Figure 5 shows the probable location of drainage line structures like check dam, gully plug, stop dam, and boulder check. The IMSD guideline has been used to finalize the location of the structure with the priority of structure in the catchment command area. As already discussed, the study

area is highly undulating and rainfall intensity is higher which causes soil erosion and increases the width of the drainage line, because of the topography and climate scenario, most of the area is covered under check dam suitability.

\begin{tabular}{|c|c|c|c|}
\hline Raster Layers & $\begin{array}{l}\text { \% Infuence } \\
\text { (Weight } \\
\text { Assigned) }\end{array}$ & Feature Classes & $\begin{array}{l}\text { Feature Weight } \\
\text { Scale Value }\end{array}$ \\
\hline \multirow{6}{*}{ Slope } & \multirow{6}{*}{18} & $\begin{array}{c}\text { Very Gently Slope } \\
(1-3 \%)\end{array}$ & 5 \\
\hline & & \begin{tabular}{|c|} 
Gently Sloping (3- \\
$5 \%)$
\end{tabular} & 7 \\
\hline & & \begin{tabular}{|c|}
$\begin{array}{c}\text { Moderately Sloping } \\
(5-10 \%)\end{array}$ \\
\end{tabular} & 9 \\
\hline & & \begin{tabular}{|c|}
$\begin{array}{c}\text { Strongly Sloping } \\
(10-15 \%)\end{array}$ \\
\end{tabular} & 7 \\
\hline & & $\begin{array}{c}\text { Mod. Steep to Steep } \\
(15-30 \%)\end{array}$ & 3 \\
\hline & & \begin{tabular}{c|} 
Steep Sloping \\
$(>30 \%)$
\end{tabular} & 3 \\
\hline \multirow{4}{*}{ Soil (HSG) } & \multirow{4}{*}{10} & HSG Group A & 4 \\
\hline & & HSG Group B & 5 \\
\hline & & HSG Group C & 9 \\
\hline & & HSG Group D & 7 \\
\hline \multirow{5}{*}{ LULC } & \multirow{5}{*}{10} & Agriculture & 9 \\
\hline & & Fallow Land & 7 \\
\hline & & Forests & 3 \\
\hline & & River/Waterbodies & 4 \\
\hline & & Barren Land & 5 \\
\hline \multirow{5}{*}{$\begin{array}{l}\text { Drainage } \\
\text { Density }\end{array}$} & \multirow{5}{*}{5} & $<2.5$ & 3 \\
\hline & & $2.5-3$ & 4 \\
\hline & & $3-3.5$ & 5 \\
\hline & & $3.5-4$ & 7 \\
\hline & & $>4$ & 9 \\
\hline \multirow{4}{*}{$\mathrm{CN}$} & \multirow{4}{*}{15} & $<50$ & 4 \\
\hline & & 60 & 5 \\
\hline & & 70 & 9 \\
\hline & & $>80$ & 7 \\
\hline \multirow{6}{*}{ Soil Depth } & \multirow{6}{*}{11} & $35 \mathrm{~cm}$ & 3 \\
\hline & & $43 \mathrm{~cm}$ & 5 \\
\hline & & $50 \mathrm{~cm}$ & 5 \\
\hline & & $56 \mathrm{~cm}$ & 7 \\
\hline & & $60 \mathrm{~cm}$ & 8 \\
\hline & & $75 \mathrm{~cm}$ & 9 \\
\hline \multirow{4}{*}{$\begin{array}{c}\text { Design } \\
\text { Discharge (Q } \\
\text { Peak) }\end{array}$} & \multirow{4}{*}{18} & $25(\mathrm{~m} 3 / \mathrm{sec})$ & 4 \\
\hline & & $35(\mathrm{~m} 3 / \mathrm{sec})$ & 5 \\
\hline & & $45(\mathrm{~m} 3 / \mathrm{sec})$ & 9 \\
\hline & & $57(\mathrm{~m} 3 / \mathrm{sec})$ & 7 \\
\hline \multirow{5}{*}{ Lithology } & \multirow{5}{*}{13} & Quartzite & 7 \\
\hline & & Granite & 9 \\
\hline & & Gabro & 4 \\
\hline & & Meta Rayolite & 5 \\
\hline & & Laterite & 3 \\
\hline
\end{tabular}

Table 2: Weight and scale value given to different layer 


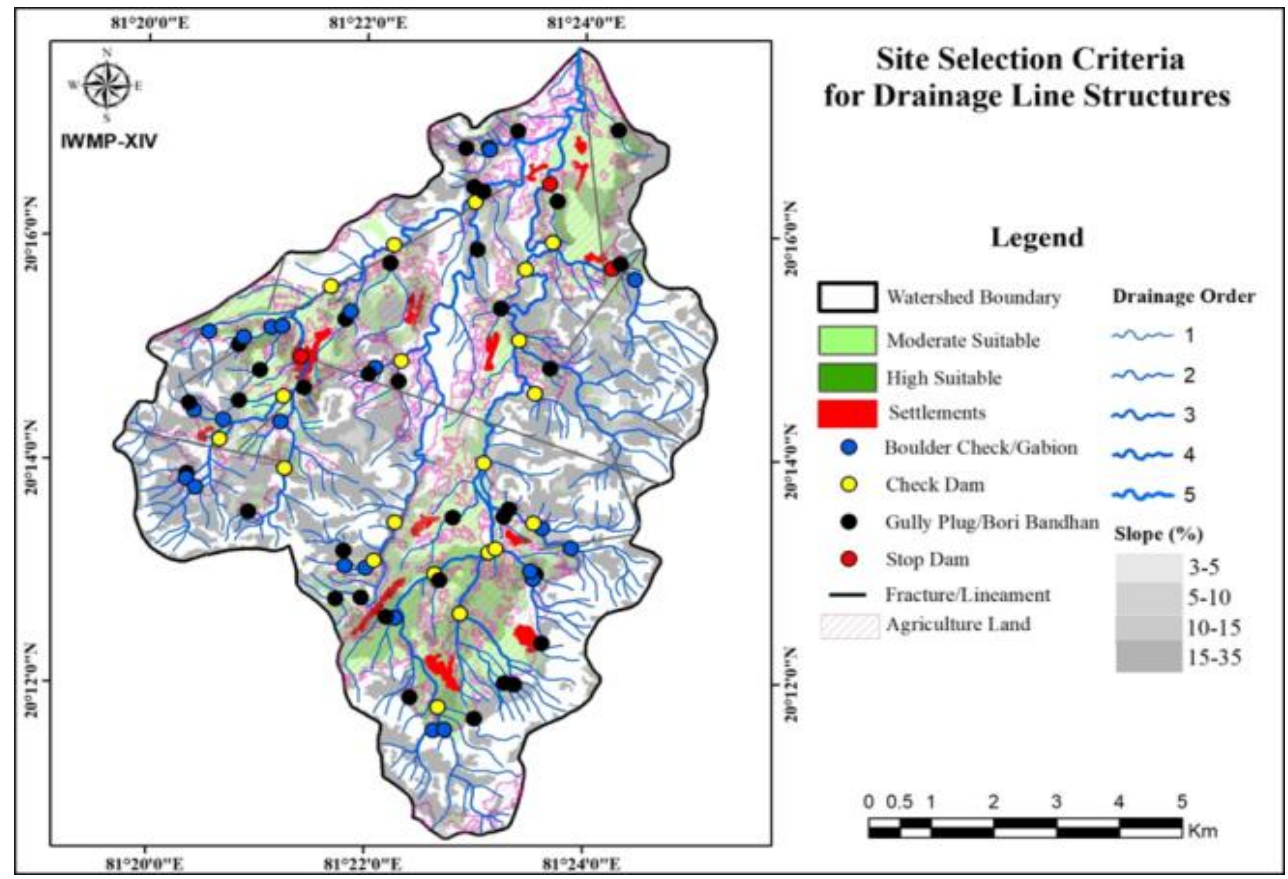

Figure 5: Suitable sites for drainage line structures

\section{CONCLUSION}

Potential zone identification for water harvesting structure has been done using AHP. The eight thematic layers, which are prepared in ArcGIS has been used to identify the probable zones in the Mandri river watershed in Kanker district of Chhattisgarh, India. Criteria to use different layer is mainly based on the features of the watershed that mainly generate the runoff like slope, the area of overland flow, drainage etc. drainage like structure located with the help of IMSD guidelines that define the structure to the priority of drainage order, slope, soil depth, HSG, land use. Results concluded that structures location identification needs expert opinion with respect to local topography.

\section{REFERENCES}

Adham, A., Riksen, M., Ouessar, M., \& Ritsema, C. (2016). Identification of suitable sites for rainwater harvesting structures in arid and semi-arid regions: A review. International Soil and Water Conservation Research, 4(2), 108-120.

Kahinda, J. M., Taigbenu, A. E., Sejamoholo, B. B. P., Lillie, E. S. B., \& Boroto, R. J. (2009). A GIS-based decision support system for rainwater harvesting (RHADESS). Physics and Chemistry of the Earth, Parts $\mathrm{A} / \mathrm{B} / \mathrm{C}, 34(13-16)$, 767-775.

Khonkaen, P., \& Cheng, J. D. (2011). The application of check dams construction to watershed management: a case study in the North of Thailand.

Krois, J., \& Schulte, A. (2014). GIS-based multi-criteria evaluation to identify potential sites for soil and water conservation techniques in the Ronquillo watershed, northern Peru. Applied Geography, 51, 131-142.

Kumar, M. G., Agarwal, A. K., \& Bali, R. (2008). Delineation of potential sites for water harvesting structures using remote sensing and GIS. Journal of the Indian Society of Remote Sensing, 36(4), 323-334.

Morais, J. O., Pinheiro, L. S., Medeiros, C., \& Pitombeira, E. S. (2006). The gabions for the protection of Caponga Beach, Ceará/Brazil: hazards and management. $J$ Coastal Res SI, 39, 848-851.

Naseef, T. A. U., \& Thomas, R. (2016). Identification of Suitable Sites for Water Harvesting Structures in Kecheri River Basin. Procedia Technology, 24, 7-14.

Patil, M. (2016). Stream flow modeling for ranganadi hydropower project in India considering climate change. Current World Environment, 11(3), 834.

Ramakrishnan, D., Durga Rao, K. H. V., \& Tiwari, K. C. (2008). Delineation of potential sites for water harvesting structures through remote sensing and GIS techniques: a case study of Kali watershed, Gujarat, India. Geocarto International, 23(2), 95-108.

Ramaswamy, S. M., \& Anbazhagan, S. (1997). Criteria and techniques of detecting site-specific mechanisms for artificial-recharge: A case study from Ayyar basin.

Rao, K. D., Rao, V. V., \& Roy, P. S. (2005). Water resources development-Role of Remote sensing and Geographical information system.

Saaty R. W. (1987). The Analytic Hierarchy Process - What it is and How it is Used. Mathematical Modelling, 9(3), 161-176. 